\title{
Oral Health Status of Children between Five Years and Eight Years of Age in Rural Areas of a District in India: A Cross-sectional Study
}

\author{
Murugaboopathy Vikneshan ${ }^{1}$, PM Preethi $^{2}$, Murugappan Senthil ${ }^{3}$, Mohandoss Suganya ${ }^{4}$
}

\begin{abstract}
Introduction: Oral health is an essential component of health throughout life. India is a developing country with a huge population; and because of the diverse nature, our country faces many challenges in rendering services to the oral health needs of the population. Majority of our country's population reside in rural area and among those $40 \%$ are children. Hence, it is highly important to recognize the oral health status and needs of children. Hardly any information is available on the oral health status of children, so the present study was conducted among 5-8-year-old children in the schools of rural Thanjavur.

Materials and methods: A total of 204 children were examined according to the World Health Organization (WHO) oral health assessment form 2013.

Results and discussion: This study shows that an alarming rate of gingivitis and $70 \%$ of the children between 5 years and 8 years of age are affected by dental caries, which is more than the national average. Preventive approaches seem to be a viable alternative to tackle the overwhelming problem of dental caries and other oral diseases.

Conclusion: The systematic implementation of preventive oral care and community-oriented health programs are needed for the continuous promotion of oral health in the rural regions of Thanjavur.

Keywords: Children, Dental caries, Oral health.

Journal of Scientific Dentistry (2019): 10.5005/jp-journals-10083-0905
\end{abstract}

\section{INTRODUCTION}

Oral health has always been an inseparable part of general health and affects the total well-being of the individuals. An individual obtains essential nutrients necessary for his/her body only by chewing and swallowing food, which is a critical function and provides the building blocks for the overall health. ${ }^{1}$ The unique characteristic of oral and dental diseases is that they are universally prevalent, do not undergo remission or termination if untreated or require technically demanding expertise and time-consuming professional treatment. Dental caries and periodontal diseases are the two globally leading oral afflictions, according to the World Oral Health Report 2003. ${ }^{2}$

However, millions of individuals suffer from dental caries and periodontal diseases, resulting in unnecessary pain; difficulty in chewing, swallowing, and speaking; and increased medical costs.

In India, oral health status of children has been documented by various investigators. National oral health survey (2003) reported a prevalence of $53.8 \%$ caries experience in 12-year-old, mean decayed, missing, and filled teeth (DMFT) and sic of 1.8 and 3 , respectively. The majority of children aged 12 years had caries in one or more of their total number of teeth. ${ }^{3}$

Multiple surveys and studies regarding the incidence and prevalence rates of dental caries are being undertaken in the past few years, and these studies have been reporting regional and international differences in the incidence and prevalence of dental caries. One consistent finding reported by all studies is that the prevalence of dental caries is decreasing in developed countries, whereas there is an increase in the developing countries. Decreased prevalence of dental caries in developed countries can be attributed to changing lifestyle and behavior patterns, increased dental
${ }^{1-3}$ Department of Public Health Dentistry, Indira Gandhi Institute of Dental Sciences, Sri Balaji Vidyapeeth (a Deemed University), Pillayarkuppam, Puducherry, India

${ }^{4}$ Department of Paedodontics and Preventive Dentistry, Indira Gandhi Institute of Dental Sciences, Sri Balaji Vidyapeeth (a Deemed University), Pillayarkuppam, Puducherry, India

Corresponding Author: Murugaboopathy Vikneshan, Department of Public Health Dentistry, Indira Gandhi Institute of Dental Sciences, Sri Balaji Vidyapeeth (a Deemed University), Pillayarkuppam, Puducherry, India, Phone: +91 9500520798, e-mail: drvikneshan@gmail.com

How to cite this article:Vikneshan M, Preethi PM, Senthil M, Suganya M. Oral Health Status of Children between Five Years and Eight Years of Age in Rural Areas of a District in India: A Cross-sectional Study. J Sci Dent 2019;9(1):2-5.

Source of support: Nil

Conflict of interest: None

awareness, less intake of refined sugars, and widespread use of fluoridated toothpaste and utilization of the dental care services. Contrary to this, increase in dental caries in developing countries can be related to factors such as industrialization, changing living standards, rapid urbanization, and intake of more refined carbohydrates.

Periodontal diseases have been accepted as one of the most widespread diseases of mankind by WHO. If untreated, it can release bacteria in blood stream and worsen the condition of patients with heart diseases and other similar ailments.

Dental fluorosis occurs as a result of disruption in enamel development, and it is seen as opacities in enamel. Oral mucosal 
lesions may be congenital or acquired and are most frequently an oral manifestation of underlying systemic disease/condition.

India is a rapidly growing nation in terms of population and economic growth. Almost $31 \%$ of the total population belongs to the age-group of 0-14 years. ${ }^{4}$ This age-group forms a significant proportion of Indian population today and is likely to further increase in the years ahead. Further, 5 years is a WHO recommended index age for oral health surveys. Hence, a cross-sectional clinical study was undertaken to determine the oral health status of children between 5 years and 8 years of age, which evaluated the prevalence of dental caries, gingival status, oral mucosal lesions, missing teeth, filled teeth, dental trauma, and enamel fluorosis. Such studies have been conducted in the districts of Vellore, Chennai, Dharmapuri, etc., and no such studies have been carried out in Thanjavur and hence this study was planned.

\section{Materials and Methods}

This is a cross-sectional study conducted to evaluate the oral health status of children aged between 5 years and 8 years in the rural areas around Thanjavur. Cluster random sampling was used to select the samples.

The sample size was calculated using the formula, $n=4 p q / 12$, where $n$ is the sample size, $p$ is the approximate prevalence rate of the disease, $q$ is $1-p$ and $l$ is the permissible error in the estimation of $p .^{5}$ The approximate prevalence was taken as $65 \%$. Children from both private and government schools were included. Among the three schools, the study subjects were selected by using systematic random sampling procedures. A total of 81 schoolchildren were examined in each selected school. The age-group of 5-15 years were selected to screen the primary dentition and mixed dentition. Informed written consent was obtained from school authorities and parents of participating children. All children enrolled at the school were given a parent introduction letter with an attached consent form. Visit to the school was made on predecided dates and all the students present on the day were examined. Children with the assent to participate in the survey were examined within their school premises. In all, 204 members were selected for this study. The "WHO's oral health assessment form for children 2013" was used as the proforma to collect data.

One examiner examined on an average of 30 students/day by gloved hand using mouth mirror and shepherd hook explorer in natural light (type III examination). Throughout the study, the examiner was assisted by an assistant in making entries in survey

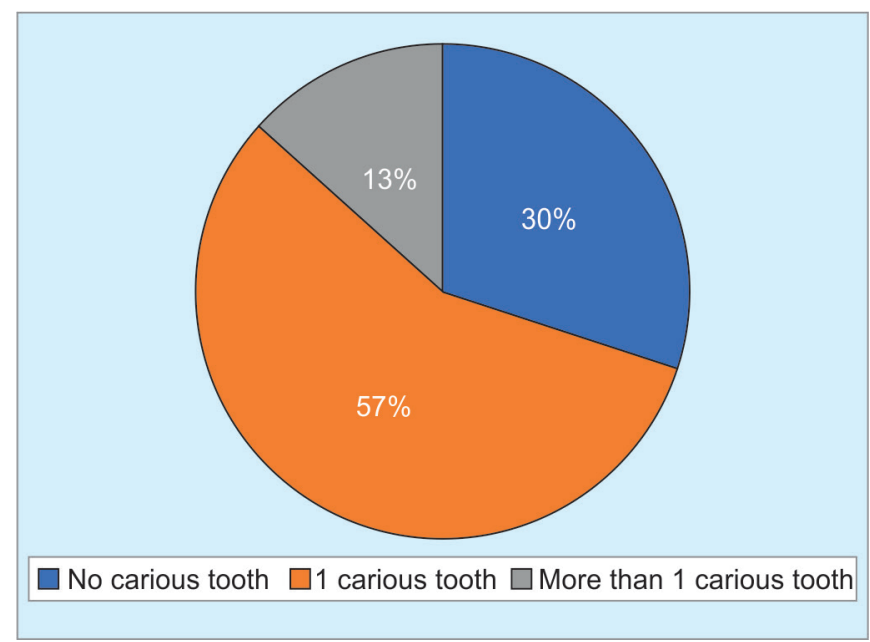

Fig. 1: Prevalence of dental caries form. The collected data were entered in Microsoft Excel for finding the frequency distribution, and percentages were calculated using SPSS 15 for windows.

\section{Result}

A cross-sectional clinical study to determine the oral health status of children aged between 5 years and 8 years in rural areas around Thanjavur reveals the following:

- Prevalence of dental caries in children (Fig. 1). This shows that $70 \%$ of the children are affected by dental caries, which is more than the national average.

- Prevalence of filled teeth (Fig. 2).

- Gingival status (Fig. 3). This shows that all the children in the sample group had teeth that were bleeding on probing.

- Prevalence of dental trauma (Fig. 4). Only $2 \%$ of the children showed evidence of dental trauma.

- Prevalence of enamel fluorosis (Fig. 5). Only $2 \%$ of the children presented with features of enamel fluorosis.

- Prevalence of oral mucosal was found to be 0 .

\section{Discussion}

The study estimated the prevalence rates of various dental diseases. The prevalence of dental caries in children aged between 5 years and 8 years belonging to rural areas around Thanjavur was $70 \%$. Therefore, this study proves that there is a high prevalence of dental caries in children in this region, and all the children in the sample group had teeth that were bleeding on probing, which means they were all affected with gingivitis.

Dental caries is an irreversible microbial disease of the calcified tissues of teeth, which is characterized by demineralization of the inorganic portion and destruction of the organic substance of the tooth, which often leads to cavitation. Although the prevalence of dental caries has declined worldwide in the past few years, it still affects children the most. ${ }^{5}$ Dental caries is the most common of all the oral diseases in childhood, i.e., from the first through the twelfth year of life. In this crucial period, the primary teeth erupt, function, and exfoliate; and the permanent teeth, exclusive of third molars, are formed and erupt into a functional pattern. ${ }^{5}$

The findings of several investigators indicate that at 1 year of age approximately $5 \%$ of the children exhibit dental caries.

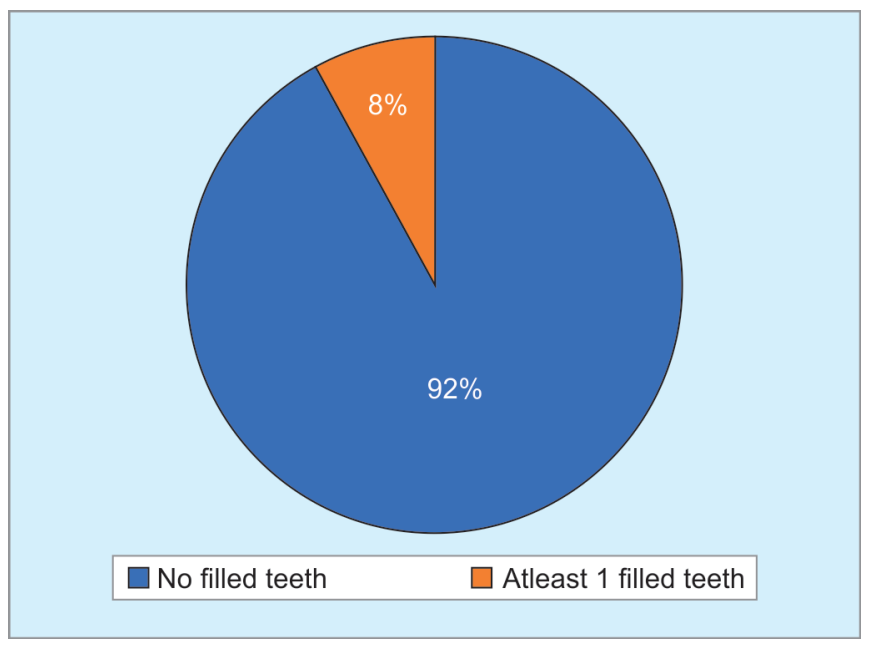

Fig. 2: Filled teeth 


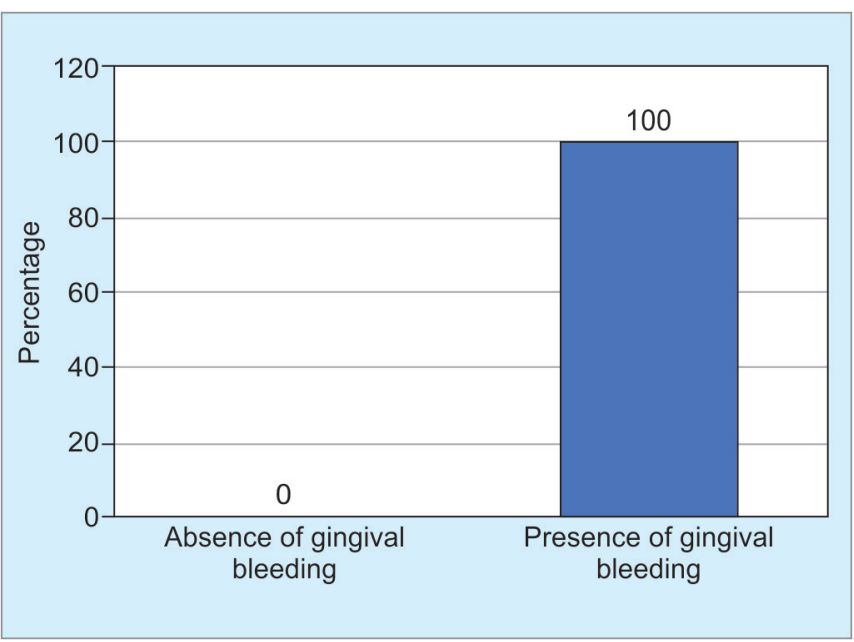

Fig. 3: Gingival bleeding

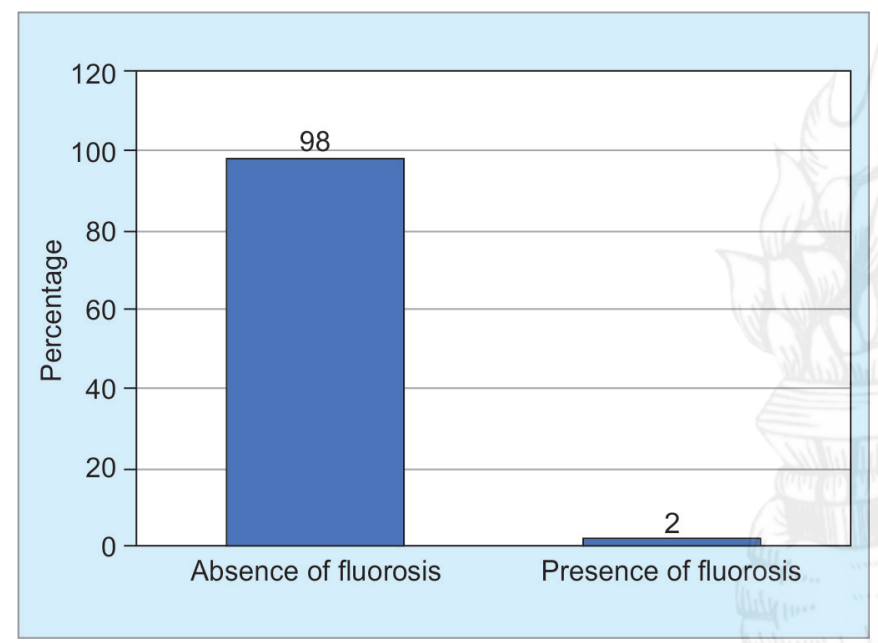

Fig. 5: Enamel fluorosis

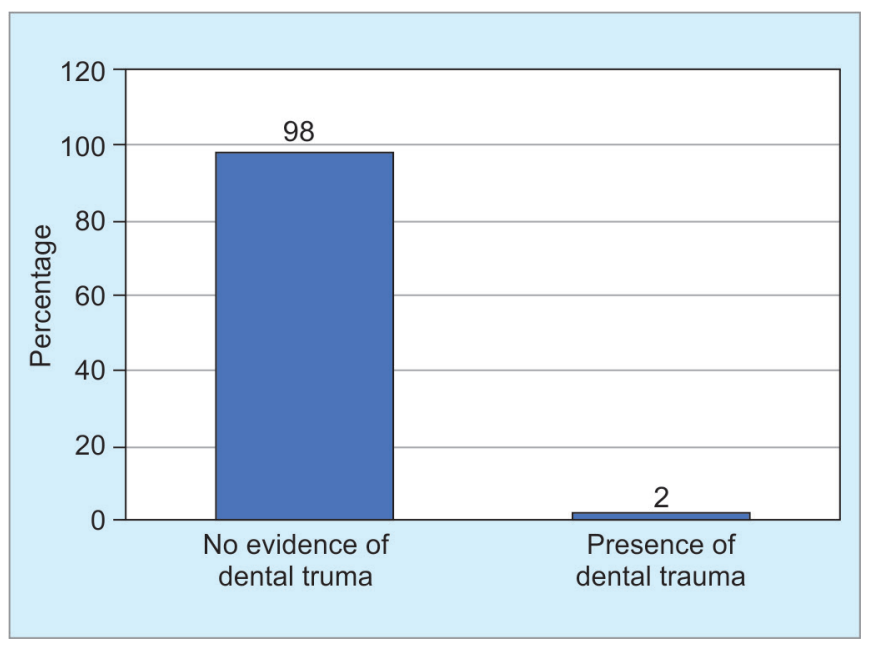

Fig. 4: Dental trauma

The percentage increases up to $10 \%$ at 2 years of age. The trend continues and the age of 5 , three out of four preschool children have carious primary teeth. ${ }^{6}$

A considerable number of surveys have been done on dental caries in the permanent dentition. These studies in general agreed that $20 \%$ of the children at age 6 have experienced tooth decay in their permanent teeth. A rapid increase follows and $60 \%$ at the age of 8 and $85 \%$ at the age of 10 are affected by dental caries. At age 12 , when most of the permanent teeth have erupted, over $90 \%$ of schoolchildren have experienced dental caries. ${ }^{7}$

The number of children with caries in industrialized countries is currently estimated to exceed $80 \%$ of the population, and in underdeveloped countries the caries rate is thought to be much higher. $^{8}$

Many studies have evaluated the oral health status of schoolchildren in many parts of Tamil Nadu and also other places of India, but no studies reported on the oral health status of Thanjavur children, hence the present cross-sectional study was conducted among 204 schoolchildren of both private- and government-sector schools (Table 1).

Table 1: Prevalence of oral diseases in other states

\begin{tabular}{|c|c|c|c|c|c|}
\hline Author & Place & $\begin{array}{l}\text { Age-group } \\
\text { (years) }\end{array}$ & $\begin{array}{l}\text { Dental caries } \\
\text { prevalence }\end{array}$ & Oral hygiene & Fluorosis \\
\hline \multirow[t]{2}{*}{ Mahesh Kumar et al. ${ }^{9}$} & \multirow[t]{2}{*}{ Chennai, Tamil Nadu } & 5 & $3.51 \pm 2.96$ & \multirow[t]{2}{*}{$80 \%$ good oral hygiene } & \multirow{2}{*}{$\begin{array}{l}5 \text { years }<1 \% ; \\
12 \text { years } 2.5 \%\end{array}$} \\
\hline & & 12 & $3.94 \pm 3.23$ & & \\
\hline Moses et al. ${ }^{8}$ & Chidambaram, Tamil Nadu & $5-15$ & $63.83 \%$ & & \\
\hline \multirow[t]{2}{*}{ Sukhabogi et al. ${ }^{10}$} & \multirow[t]{2}{*}{ Hyderabad, Andhra Pradesh } & 12 & $41.4 \%$ & \multirow{4}{*}{$\begin{array}{l}\text { Good oral } \\
\text { hygiene-39.1\% }\end{array}$} & \\
\hline & & 15 & & & \\
\hline Poornima et al. ${ }^{11}$ & Davanagere city, Karnataka & $8-9$ & $60.1 \%$ & & \\
\hline Kalaskar et al. ${ }^{12}$ & Vidarbha region, Maharashtra & $6-16$ & $65.70 \%$ & & \\
\hline Arora and Bhateja ${ }^{13}$ & Mathura city, Uttar Pradesh & 12 & $57 \%$ & $\begin{array}{l}84 \% \text { _ good oral hygiene; } \\
16 \% \text {-fair oral hygiene }\end{array}$ & \\
\hline Behal et al. ${ }^{14}$ & Kashmir, J \& K & $6-12$ & $45.48 \%$ & $42.8 \%$ good oral hygiene & \\
\hline Prasad et al. ${ }^{15}$ & $\begin{array}{l}\text { West Godavari district, } \\
\text { Andhra Pradesh }\end{array}$ & $11-14$ & $63.5 \%$ & & \\
\hline Hiremath et al. ${ }^{16}$ & Belagavi district, Karnataka & $6-11$ & $78.9 \%$ & & \\
\hline Abraham et al. ${ }^{17}$ & Malappuram, Kerala & $12-13$ & $71.4 \%$ & & \\
\hline Sonika et al. ${ }^{18}$ & Chandigarh & $3-6$ & $48.3 \%$ & & \\
\hline
\end{tabular}


This region requires immediate and meticulous intervention for dental caries and gingivitis, as the prevalence rates are alarmingly high among these two dental diseases. There is a need for dental health program to target the population and there is a need for school health education program to educate the children. Parents and schoolteachers will also be benefitted from oral health education and they should be advised regarding the dental followups with dietary instructions to maintain good oral hygiene. It is recommended that children under the age of 6 years, brushing with fluoridated toothpaste should be supervised to prevent systemic ingestion.

Regarding the preventive program, most of the children need pit and fissure sealant application. But the feasibility of pit and fissure sealants in Indian scenario is questionable. However, on priority basis for selected group of schoolchildren, pit and fissure sealant application can be taken as preventive measures.

\section{Recommendation}

The systematic implementation of preventive oral care and community-oriented health programs is needed for the continuous promotion of oral health. Professional dental follow-up can be integrated in the medical follow-up. Parents and schoolteachers will be benefitted from oral health education, and they should be advised regarding the dental follow-ups with dietary instructions to maintain good oral hygiene.

\section{LiMITATION}

This is a cross-sectional study conducted in a rural district of Tamil Nadu and hence its reflection on the overall health status of children residing in various parts of our country is questionable due to the diverse nature of our country.

\section{Conclusion}

The awareness regarding the oral health was very minimal among the study participants. It may be due to ignorance, lack of knowledge, or the lack of motivation. The ideal and the affordable strategy to tackle the problem at the primary level itself is necessary. Proper and effective health education to prevent the problems at the primary level is absolutely needed. Dental health education should be made as an integral part of school curriculum.

\section{References}

1. Das UM, Beena JP, Azher U. Oral health status of 6- and 12-year-old school going children in Bangalore city: an epidemiological study. J Indian Soc Pedod Prev Dent 2009;27(1):6-8. DOI: 10.4103/09704388.50809.

2. Singhal DK, Acharya S, Thakur AS. Dental caries experience among pre-school children of Udupi taluk, Karnataka, India. J Oral Health Community Dent 2015;8(1):5-9. DOI: 10.5005/johcd-9-1-5.
3. Saravanan S, Anuradha KP, Bhaskar DJ. Prevalence of dental caries and treatment needs among school going children of Pondicherry, India. J Indian Soc Pedod Prev Dent 2003;21(1):1-12.

4. http://www.censusindia.gov.in/Data_Products/Library/Indian_ perceptive_link/Census_Terms_link/censusterms.html. [Last accessed on 2016 Dec 03].

5. Peter S. Essentials of preventive and community dentistry, 5th ed., New Delhi: Arya Medi Publishing House Pvt., Ltd; 2006.

6. World Health Organization. Oral health survey, basic methods, 5th ed., Geneva: World Health Organization; 1997.

7. Finn SB. Clinical pedodontics, 4th ed., Delhi: Laxman Chand Arya; 1995.

8. Moses J, Rangeeth BN, Gurunathan D. Prevalence of dental caries, socio-economic old school going children of Chidambaram status and treatment needs among 5 to 15 -year-old school going children of Chidambaram. J Clin Diagn Res 2011;5(1):146-151.

9. Mahesh Kumar P, Joseph T, Varma RB, Jayanthi M. Oral health status of 5 years and 12 years school going children in Chennai city-an epidemologial study. J Indian Soc Pedod Prev Dent 2005;23(1):17-22. DOI: 10.4103/0970-4388.16021.

10. Sukhabogi JR, Shekar CBR, Hameed IA, Ramana IV, Sandhu G. Oral health status among 12 and 15-year-old children from government and private schools in Hyderabad, Andhra Pradesh, India. Ann Med Health Sci Res 2014;4(Suppl 3):S272-S277. DOI: 10.4103/21419248.141971.

11. Poornima P, Disha P, Pai SM, Nagaveni NB, Roshan NM, Neena IE. Dental caries experience among 8-9-year-old school children in a South Indian city: a cross-sectional study. J Indian Assoc Public Health Dent 2015;13(2):144-147. DOI: 10.4103/2319-5932.159050.

12. Kalaskar RR, Kalaskar AR, Chandorikar H, Hazarey S. Prevalence of dental caries and treatment needs in school going children of Vidarbha region, Central India. Universal Research. J Dent 2015;5(2):68-72.

13. Arora G, Bhateja S. Prevalence of dental caries, periodontitis, and oral hygiene status among 12-year-old schoolchildren having normal occlusion and malocclusion in Mathura city: a comparative epidemiological study. Indian J Dent Res 2015;26(1):48-52. DOI: 10.4103/0970-9290.156801.

14. Behal R, Lone N, Shah AF, Yousuf A, Jan SM. Oral health status of 6-12-year-old children attending a Government Hospital in Kashmir. IAIM 2016;3(3):139-146.

15. Prasad MG, Radhakrishna AN, Kambalimath HV, Chandrasekhar S, Deepthi B, Ramakrishna J. Oral health status and treatment needs among 10126 school children in West Godavari district, Andhra Pradesh, India. J Int Soc Prev Community Dent 2016;6(3):213-218. DOI: 10.4103/2231-0762.183102.

16. Hiremath A, Murugaboopathy V, Ankola AV, Hebbal M, Mohandoss S, Pastay P. Prevalence of dental caries among primary school children of India - a cross-sectional-study. J Clin Diagn Res 2016;10(10): ZC47-ZC50. DOI: 10.7860/JCDR/2016/22474.8642.

17. Abraham A, Pullishery F, Raghavan R. Dental caries and calculus status in children studying in Government and Private Schools in Malappuram, Kerala, India. IAIM 2016;3(3):35-41.

18. Sonika R, Goel S, Vijaylakshmi S, Goel NK. Prevalence of dental caries and its association with Snyder test among preschool children in anganwadis of a North Indian city. Int J Public Health Dent 2012;3(1):1-10. 